\title{
STUDYING THE IMPLEMENTATION OF POTENTIOMETRIC METHODS FOR THE DETECTION OF CRACKS IN RENOVATION OF FORGING TOOLS
}

\begin{abstract}
Mass production using forging tools leads to an enormous increase in the consumption of forging tools and the need for rapid and flexible tool renovations. A major shortcoming in the renovations is the failure to identify cracks propagating from the surface towards the core of the basic components. Forging tools made from special tool steels are highly cost-intensive. The main cost component is the price of the material, heat treatment and other chemical-heat treatment surfaces. This is the main reason why it is necessary to think about renovation at the design stage, in case of the need for repairs. An important factor in the renovation process is the optimal choice of technology to restore the mechanical and physical properties of tools at an acceptable price, of course. The main issue in the choice of the optimal technology is heat treatment to achieve a high hardness and surface of the die, which is nitrided to ensure wear resistance. This article deals with the application of non-destructive detection technology when considering the size of die forging defects that arise in the process of forming.
\end{abstract}

Keywords: Forging tools, renovations, potentiometric methods, crack detection.

\section{Introduction}

Forging is one of the most economical manufacturing methods for making parts from steel and non-ferrous metals. Its advantages in comparison to other methods are: significant savings in materials, higher production rate, better grain structure and better surface quality. The materials from which forging tools are made must comply with the high demands of the mechanical, physical and chemical aspects of high strength, toughness and hardness. The technical and technological process depends on these requirements, which directly affect the cost of the individual components and their competitiveness [1] The impact of satisfying these demands is that the tool will have a longer shelf life, and thus there will be less downtime for replacement and repair. In this way, we can make better use of production machinery and equipment. Generally, when machining materials with more difficult machinability and high hardness, we use methods with non-cutting technologies that achieve high productivity, flexibility and excellent functional properties [2 and 3].

Heat distribution and temperature fluctuations on the surfaces of forging tools cause plastic deformation, and the influence of thermo-mechanical stress leads to thermal fatigue and the formation of surface cracks. These defects significantly affect the quality of finished forgings and forging die life itself. To capture and track these defects there are several procedures, whether destructive or non-destructive methods, for the detection of cracks within. As regards forging dies, the solution is to use non-destructive methods that do not disturb the shape and surface components [4 and 5].

For mass production, die forging is used (Fig. 1), whereby the principle is that the heated material takes on the final shape of the die cavity with one or more strokes. This can ensure a more accurate shape than with free forging. The accuracy of the surface can be significantly improved by further finishing operations such as calibration, and to achieve a high quality surface, which would not require further machining. Die forging makes it possible to achieve a major reduction of material and fibres reflecting the contour of die forging, which has a positive effect on the mechanical properties of the material [6 and 7].

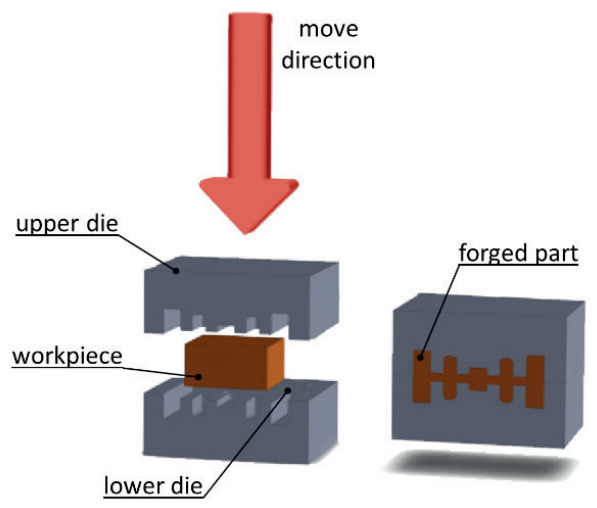

Fig. 1 The principle of die forging

\footnotetext{
* Jozef Pilc, Michal Derbas, Miroslav Janota, Mario Kosut

Department of Machining and Manufacturing Technology, Faculty of Mechanical Engineering, University of Zilina, Slovakia

E-mail: jozef.pilc@fstroj.uniza.sk
} 
The workpiece is inserted into the lower die. By action of energy, the shaping machine moves one part of the die against the other while the starting material fills the cavity. By fully grasping, the die cavity is filled and transformed into the desired shape. The procedure for filling a cavity influences the speed of deformation, which depends on the type of machine. The effect of impact hammers causes more rapid creep in the direction of shock and the force of the press results in better filling of the cavities in a direction perpendicular to the acting force. These differences in filling the die cavity influence the choice of the type of moulding machines and choice of forging operations for the part [7 and 8].

\section{Cracks and their growth in the forging tool}

The formation of fatigue cracks is explained by various models. One of the basic models takes the idea of formation of intrusions and extrusions with recurring shear in one or two shear systems. The relative motion of individual shear belts allows deepening of the intrusion and crack formation. If the loaded body has construction, metallurgical or technological notches, the first phase of crack growth will not arise [9 and 10]. By gradual cyclic stresses, the crack penetrates to the depth of the body, after which the crack deviates perpendicularly to the direction of principal stress. The length of the crack, which corresponds to the transition from the first phase to the second phase of crack growth, depends on the material and amplitude size of the stress loading [11 and 12].
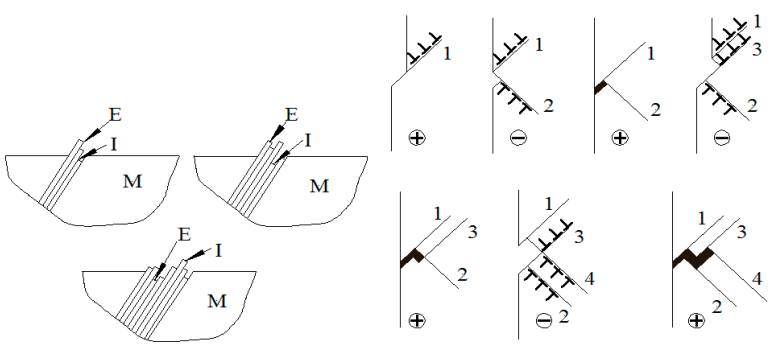

Fig. 2 Formation of micro-crack by formation of intrusions (I) and extrusions (E) in one- and two-shear systems (Neuman's model)

The forging process leads to mechanical stress that causes wear on the shape of the die (Fig. 2) and also fatigue fracture which reduces the required quality of the finished forgings. Therefore, after a fixed life, the forging die is removed from the forging process and sent for repair or renovation. Cracks can occur using the wrong modes of production. Poor cooling of cast or forged parts, overheating during grinding, or excessive tension during the manufacturing process are common causes of cracks. Cracks (Fig. 3) are defined as a narrow gap, where the length along the surface is at least ten times greater than their depth in the material, and a visual example of the forging tools is shown in Fig. 4. In addition, the width of the fracture is very small, at least ten times less than the depth. The bottom of the fracture is mostly sharp, causing sharp notches in the material. Due to mechanical stress, especially when changing or alternating loads, there is a sharp notch at the bottom of the tension that can cause enlargement of cracks [14, 15 and 16].

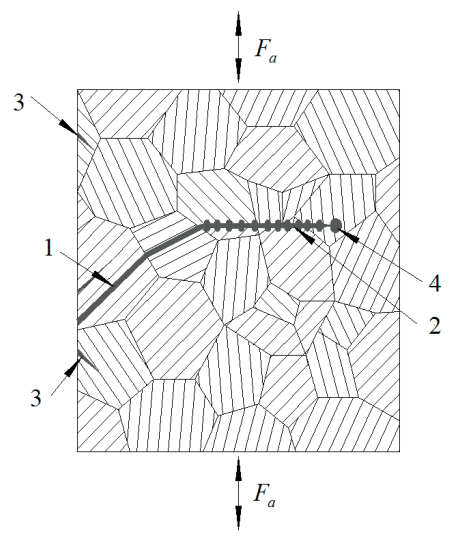

Fig. 3 Scheme of growth of fatigue crack 1 - first phase, 2 - second phase, 3 - non-effective cracks, 4 - plastic zone of the crack [13]

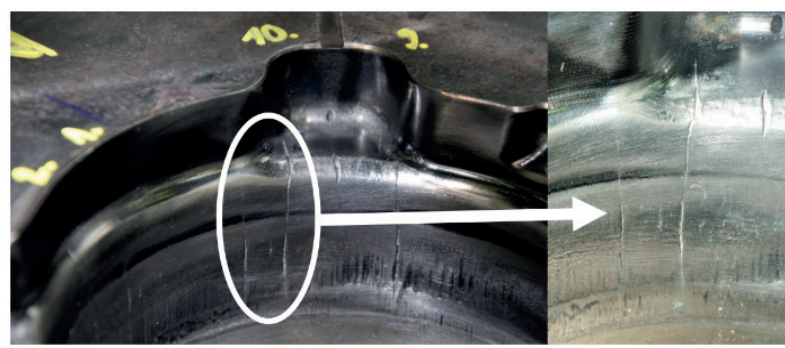

Fig. 4 Wear of die forging

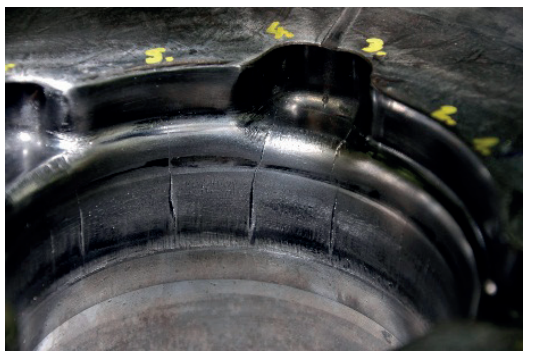

Fig. 5 Fatigue cracks on the functional surface of die forging

It is therefore very important to always pay close attention to the crack. Early detection and assessment of cracks is essential. This is especially true for surface cracks. In most cases the exposed parts, such as auto parts, experience the biggest stress generated on the surface of parts. It is also important to note that not every flaw will damage components (Fig. 5). The laws of 
crack mechanics indicate that some cracks can be tolerated. This depends on many factors and it is sometimes hard to decide on the use of standard methods or non-destructive material testing [17, 18 and 19].

\section{Renovation of die forging}

Renovation is a special case of repair where the repaired object is a machine component. It is work to renew machine parts whose functional properties are damaged. Renovation is a set of activities carried out in order to restore the operational status of components and their life. It is a repair in which the worn parts are restored to their geometric shape, original size, and functional and mechanical properties in accordance with drawings and technical specifications. Renovation may be seen as a repair sub-sector, which contributes to reducing the cost of restoration and operation of machinery, but it can also be seen as a special case of recycling materials, which, moreover, reduces the demand for raw materials and energy resources [20, 21 and 22].

Before renovation, it is necessary to map the extent of tool wear and the inferred extent of renovations and the required technology. Range is determined with respect to the size of the fracture surface that needs to be removed by the machining surface until the outer surfaces show no signs of defects. This process is usually performed by visual observation of the surface using optical devices which can find the largest size defects generated in the forging process, which are preventing efficient use. Since control is exercised subjectively by a worker who often cannot assess the degree of wear, not least the size of the fracture, the process is repeated until all defects are removed. It often happens that the extent of wear is destructive for the die, which is can be detected by only a few controls and subsequent surface treatment. From an economic point of view, the time required for renovation and extension of the life, causes costs to rise. Sometimes it is necessary to completely remove the forging dies for the renovation process due to excessive wear and damage. This process is well run and widely used in practice, and, therefore, seeks to simplify and intensify the technology of renovations [23, 24 and 25]

For this purpose, there are various methods involving surveys of defects in materials and products using either destructive or non-destructive detection technology, which is able to assess the extent of wear and thus indicate more options for the renovation. The best approach to renovation, and also a non-destructive method, is defectoscopy, due to its ability to change the status of the sample for future use (Fig. 6) [1].
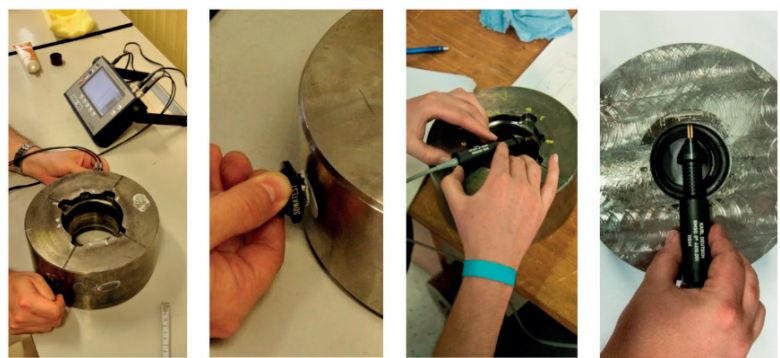

Fig. 6 The process of examining cracks by the potentiometric method with $R M G 4015$ device

\section{Crack mapping by potentiometric defectoscopy}

The principle of the potentiometric method is shown in Fig. 7. Electric current (with intensity $I$ ) is supplied to the examined sample via electrodes $E_{1}$ and $E_{2}$. Voltage electrodes $N_{1}$ and $N_{2}$ measure the potential $U_{0}$ in the surface layer at a distance $l_{0}[26]$.

$U_{0}=R \cdot I=\frac{\rho \cdot l_{0}}{S} \cdot I$

where $R$ - resistance between $N_{1}$ a $N_{2}, \rho$ - resistivity of material, $S$ - cross-sectional area of material

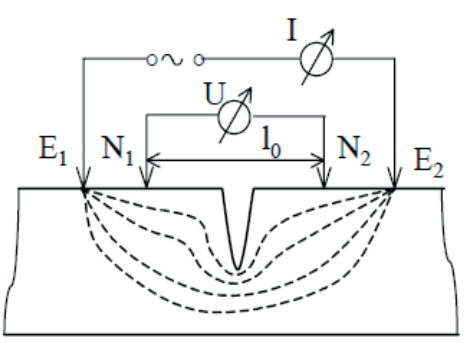

1. Calibration

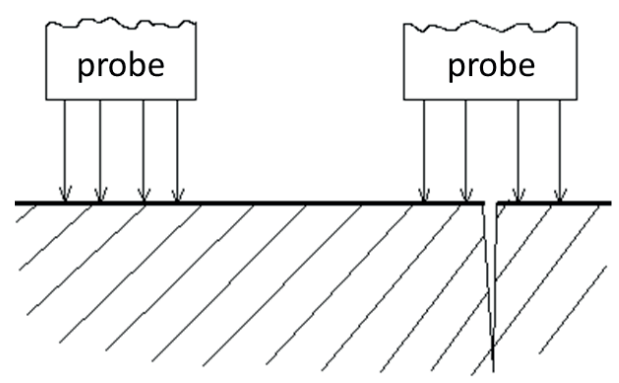

Fig. 7 Principle (left) and process (right) of measuring [26]

For good functioning of this process, four electrodes are necessary: two for electric current and two for voltage. For the most accurate measurements, the voltage electrodes must be between the electrodes for electric current. All the tips of the 
electrodes are sprung, therefore contact pressure is exerted by the tip on the surface. Due to this fact, reliable contact is ensured also on uneven surfaces [2 and 27].

Measurement of crack depth is usually a comparative measurement. Comparison between the decrease of voltage on the intact surface and the surface with the crack identifies the depth of the crack. One advantage of the potentiometric method is that the width of the crack has no effect on the measured values, if this crack is narrower than the distance between electrodes [2 and 28].

\section{Experimental results and discussion}

For crack depth detection the potentiometric device RMG 4015 was used. The examined sample is a forging die with recesses and a cylindrical course of inner cavity (Fig. 8). This forging die performs a die forging with recesses and a cylindrical inner cavity.

As seen in Fig. 9, the measured values of the depth of cracks, the maximum depth of the crack is located at the edge of the die. The course of the crack is significantly different from the other measured cracks, which are much shorter and are found mainly in the vicinity of the internal curvature of the die cavity. This crack presents a particular risk because the next time the die is used there could be further spread and deepening of the cracks, which could lead to exclusion of forging die and the inability to undertake further renovations.

In crack No. 1, the first five crack depth measurements were carried out at the top of the forging die, therefore, the depth of measurement data has the value 0 . The measurement was carried out towards the edge of the external die to the die cavity inner edge.

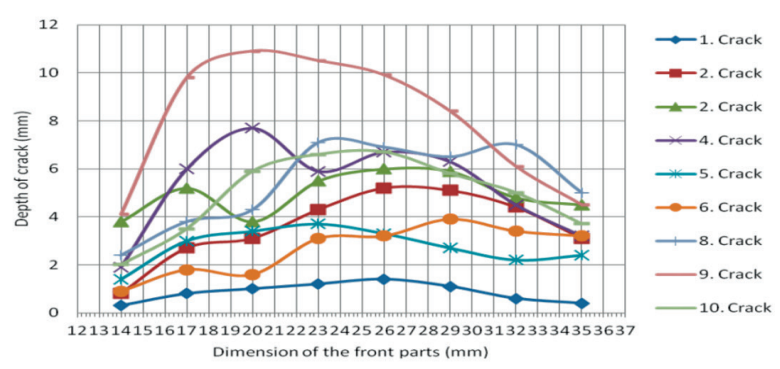

Fig. 9 Graphical representation of cracks in the forging die

From the graphic course (Fig. 9) you can see that the depth of cracks increases to a maximum and after this peak begins to fall. It is also possible to see that the cracks on the die are of different depths. Measuring the cracks using the RMG 4015 device was quick and smooth, making it possible to demonstrate the practical use of the machine in engineering practice.

\section{Conclusion}

High thermo-mechanical loading on the working surface of forging tools causes thermal fatigue and the formation of surface cracks, affecting the quality of final products and the operating life of the forging die. For monitoring of these defects, there are some procedures and methods for crack mapping, both destructive and non-destructive.
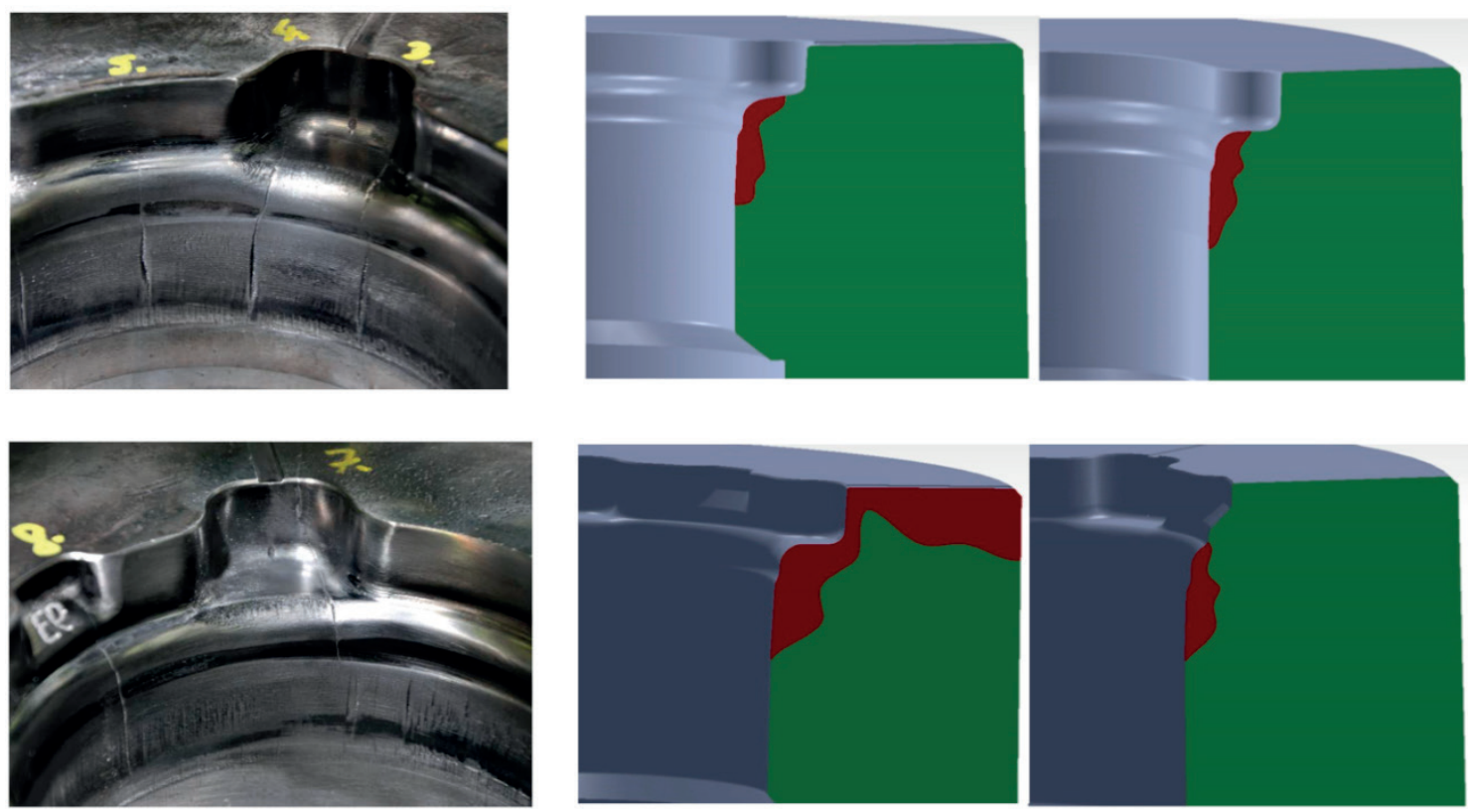

Fig. 8 Detail and course of selected cracks on forging die 
When examining the progression of cracks, the potentiometric device can detect the crack on the surface and measure its depth without destructive invasion. This device can map the crack profile, and find its origin and the direction of its progress. It can be used and applied for complicated surface profiles and cavities of parts when examining surface defects. The measurement has some limitations: the surface of the sample must be clean without any dirt and the sample must be conductive.

The potentiometric method can be applied when renovating forging tools, and for renovation generally, for example, in the area of the renovation of cutting punches where it is necessary to determine the surface defects which inhibit their use. The device can be used in the rationalization of renovation, where it is necessary to restore the functional properties of all machine parts affected by very significant wear.

\section{Acknowledgements}

The article was funded by the project with the University of Zilina OPVaV-2009/2.2/04-SORO No. 26220220101 "Intelligent system for nondestructive technologies on evaluation for the functional properties of components of X-ray diffraction”.

\section{References}

[1] DERBAS, M., CZAN, A.: Renovating Intensification of Machining Nitride Layers of Tools for Volume Forming, TRANSCOM 2011: $9^{\text {th }}$ European conference of young research and scientific workers, June, 2011, University of Zilina. ISBN 978-80-554-0374-8. - S. $57-60$.

[2] VASILKO, K., PILC, J.: New Technological Knowledge of the Rotary Turning Tool, J. Manufacturing Technology, vol. 13, No. 4, December 2013, 571-575, ISSN: 1213-2489

[3] MICHALIK, P., ZAJAC, J., HATAlA, M.: Programming CNC Machines using Computer-aided Manufacturing Software, Advanced Science Letters, vol. 19, No 2, 2013, 369-373, ISSN: 19366612

[4] SAJGALIK, M., CZAN, A.: Studying of Processes in Cutting Zone by Non-destructive Methods, Technological Engineering, vol. 8, No. 2, University of Zilina, 2011

[5] CEP, R., JANASEK A., PETRU J., CEPOVA L., CZAN A., VALICEK J.: Hard Machinable Machining of Cobalt-based Superalloy. Manufacturing Technology XIII/13, 2013, 226-231, UJEP: Usti n. Labem. ISSN 1213-2489

[6] MORAVEC, J., BOHUSOVA, Z.: Technology of Forming (in Slovak), EDIS University of Zilina, 2010, 570 p., ISBN 978-80-5540200-0

[7] ZELENY, J.: Manufacturing of Dies and Molds (in Czech). MM prumyslove spektrum SPECIAL, April 2001

[8] MOHYLA, P., TOMCIK, P., BENES, L., HLAVATY, I.: Effect of Post-welding Heat Treatment on Secondary Hardening of Welded Joints of Cr-Mo-v Steel. Metal Science and Heat Treatment, 53 (7-8), 374-378. ISSN: 0026-0673

[9] CZAN, A., TILLOVA, E., SEMCER, J., PILC, J.: Surface and Subsurface Residual Stresses after Machining and their Analysis by x-ray Diffraction. Communications - Scientific Letters of the University of Zilina, vol. 15, No. 2, 2013, 69-76. ISSN 1335-4205

[10] HOLESOVSKY, F., NAPRSTKOVA, N., NOVAK, M.: GICS for Grinding Process Optimization. Manufacturing Technology, XII/12, 2012, 22-26, UJEP : Usti n. Labem, ISSN 1213-2489

[11] DEUTSCH, V., PLATTE, M.: Crack Depth Gauging with the Potential Probe Method, Castell Publication Inc.: Wuppertal, 2003, 34 p., ISBN 3-934 255-17-5

[12] SAPIETOVA, A., SAGA, M., NOVAK, P.: Multi-software Platform for Solving of Multibody Systems Synthesis, Communications - Scientific Letters of the University of Zilina, vol. 14, No. 3, 2012, 43-48, ISSN 1335-4205

[13] PALCEK, P., HADZIMA, B., CHALUPOVA, M.: Material Characteristics (in Slovak), EDIS: University of Zilina, 2004, 163 p., ISBN 80-8070-240-3

[14] ZMINDAK, M., RIECKY, D.: Meshless Modelling of Laminate Mindlin Plates under Dynamic Loads Synthesis, Communications - Scientific Letters of the University of Zilina, vol. 14, No. 3, 2012, 24-31, ISSN 1335-4205

[15] NOVAKOVA, J., PETRKOVSKA, L., BRYCHTA, J., STANCEKOVA, D.: Influence of Cutting Parameters on Integrity Surface at High Speed Cutting. Transactions of the VSB-Technical University of Ostrava. Mechanical Series, vol. LV, No. 1, 2009, 203-209, Ostrava: VSB - TUO

[16] CEP, R., OCENASOVA, L., NOVAKOVA, J., PETRKOVSKA, L., CZAN, A., STANCEKOVA, D.: Interrupted Machining Tests of Ceramic Cutting Tools, Proc. of TMT 2009, October 2009, Hammamet, vol. 13, No. 1, 733-736, ISSN 1840-4944

[17] STANCEKOVA, D., SEMCER, J., DERBAS, M., KURNAVA, T.: Methods of Measuring of Residual Stresses and Evaluation of Residual State of Functional Surfaces by x-ray Diffractometric Methods, J. Manufacturing Technology, vol. 13, No. 4, December 2013, 547-552, ISSN: 1213-2489 
[18] PANDA, A., DUPLAK, J., VOROBEL, T., JURKO, J., FABIAN, S.: Study of the Surface Material AISI 304 usable for Actuator after the Process of Turning, Applied Mechanics and Materials, vol. 460, 2014, 107-114, ISSN: 1660-9336

[19] PILC, J., MICIETOVA, A., SALAJ, J., CILliKOVA, M.: The Influence of the Selected Aspects in Planing Operations by using Auto-rotation Tool, Transactions of Famena, vol. 29, No. 2, 2005, 55-60, ISSN: 1333-1124

[20] PARKER, D.: Remanufacturing in the UK, A Significant Contributor to Sustainable Development, Aylesbury: UK Oakdene Hollins, 245,2003

[21] NESLUSAN, M., CZAN, A., ZURPEL, U.: Analysis of the Heat Distribution when Grinding of a VT 9 Titanium Alloy and its Relation to Residual Tresses, Strojniski vestnik - J. of Mechanical Engineering, vol. 48, No. 10, 557-564, 2002, ISSN 0039-2480

[22] NAPRSTKOVA, N., HOLESOVSKY, F.: Admeasurement of Grinding Wheel Loss at FPTM. 24 $4^{\text {th }}$ Intern. colloquium Advanced manufacturing and repair technologies in vehicle industry, 159-164, 2007. ISBN 978-80-7194-962-6

[23] CZAN, A., SAJGAliK, M., HOLUBJAK, J., KOURIL, K.: Studying of Cutting Zone when Finishing Titanium Alloy by Application of Multifunction Measuring System, Manufacturing Technology, vol. 13, No. 4, 2013, 428-431, ISSN: 1213-2489

[24] CEP, R., KOURIL, K., MRKVICA, I., JANASEK, I., PROCHAZKA, J.: Testing of Kyocera Tools in Conditions of Interrupted Cut (in Czech). Strojirenska technologie, vol. XV, No. 3, 2010, 51-58, ISSN 1211-4162

[25] LUKOVICS, I., BILEK, O., HOLEMY, S.: Application of Sintered Corundum in Manufacturing of Tools (in Czech), Strojirenska technologie, XV, No. 3, 2010, 27-34, ISSN 1211-4162

[26] BAlOG, J., CHOVANEC, A., KIANICOVA, M.: Technical Diagnostics (in Slovak), GC Tech: Trencin, 2002,115 p., ISBN 80-88914-66-3

[27] CEP, R., JANASEK, A., CEPOVA, L., PETRU, J., HLAVATY, I., CAR, Z., HATALA, M.: Experimental Testing of Exchangeable Cutting Inserts Cutting Ability. Tehnicki Vjesnik, 20 (1), 2013, 21-26. ISSN: 1330-3651

[28] KOPEC, B.: Non-destructive Testing of Materials and Constructions (in Czech), 2008, CERM: Praha. 